\title{
Internasjonal satsing for bedre helse - Norges rolle 器은
}

\author{
Fattigdom og dårlig helse henger tett sammen. Nye målrettete tiltak, slik som økt vaksinasjonsdekning, \\ har bidratt til bedre barnehelse i mange land. Globale kampanjer mot enkeltsykdommer har samtidig \\ ført til en økende fragmentering av innsatsen for å bedre helse. Det er dermed fare for at andre viktige \\ helsetjenestefunksjoner kan bli nedprioritert. Norge bør bidra til å motvirke dette.
}

Engelsk oversettelse av hele artikkelen på www.tidsskriftet.no

\section{Gunnar Kvåle}

gunnar.kvale@cih.uib.no Halvor Sommerfelt

Senter for internasjonal helse

Universitetet i Bergen

Det har vist seg å være mulig å bryte den onde sirkelen mellom fattigdom og dårlig helse, men dette krever stor innsats fra flere samfunnssektorer. Ansatte i helsesektoren har en viktig rolle å spille, ikke bare i kraft av å utføre kurativt og helsefremmende arbeid, men også ved å forsøke å påvirke politikere og varsle om uakseptable forhold. Helsesektoren må utvikles på en måte som bidrar til bedre helse til en overkommelig kostnad.

\section{Fragmentering}

Det er de siste 15 årene blitt etablert et økende antall offentlig-private partnerskap for å styrke innsatsen mot sykdommer som malaria, tuberkulose, hiv/aids og andre fattigdomsrelaterte sykdommer (1). Etter tusenårsskiftet er det tatt mange nye initiativer for å oppnå FNs tusenårsmål (2). Helsebistanden fra Norge er tredoblet i løpet av de siste ti år (3), og Norge har satt av 1 milliard amerikanske dollar til bedring av barne- og mødrehelse over en tiårsperiode (4). Innsatsen fra Norge, andre giverland og internasjonale aktører som Bill og Melinda Gates' helsefond - blant annet gjennom den globale vaksinealliansen, GAVI - har bidratt til en nedgang i barnedødeligheten i mange land (5). Med midlene som ble lovet på GAVI-alliansens giverkonferanse i London i juni 2011 (6), kan alliansen begynne en betydelig oppskalering av pneumokokk- og rotavirusvaksinasjon av barn.

De mange globale kampanjene mot enkeltsykdommer eller for spesielle målgrupper har imidlertid ført til en økende fragmentering av innsatsen for bedre helse i lavinntekts- og mellominntektsland. Det er fortsatt et stort udekket behov for behandling, omsorg og forebygging av mange vanlige sykdommer, og nye initiativer kan føre til tapping av personell og ressurser fra det eksisterende helsesystemet. Ved å bidra til at flere midler avsettes til å støtte selve helsesystemet, kan Norge bidra til at internasjonale initiativer ikke drenerer, men snarere styrker viktige helsetjenestefunksjoner.

\section{Bedre koordinering}

For en bedre koordinering av ulike aktører ble det i september 2007 etablert et internasjonalt helsepartnerskap (IHP) (7), lansert av statsministrene Gordon Brown og Jens Stoltenberg, med mange land i Europa, Afrika og Asia som medspillere. Sammen med beslektede initiativer er det etablert en koordinerende prosess med en felles arbeidsplan (IHP+). Dette har medvirket til at det nå i mange land utarbeides nasjonale helseplaner (8). Målet er blant annet å bidra til å oppfylle de helserelaterte tusenårsmålene gjennom en bedre koordinering av innsatsen mellom mottakerlandene og giverne for å oppnå høyere dekningsgrad for effektive intervensjoner og nødvendige helsetjenester.

\section{Resultatbasert finansiering}

IHP+ har lagt vekt på resultatbasert finansiering (RBF) som en viktig strategi for å bedre helse og helsetjenester i lavinntektsog middelinntektsland $(9,10)$. Norge har vært en pådriver for strategien og bevilget 105 millioner dollar til Verdensbanken for bruk i perioden 2009-13 til dette formålet (11). Dette er litt overraskende på bakgrunn av at en rapport fra en IPH+- arbeidsgruppe (12) viser til at vi mangler pålitelige data for hvor gunstig det vil være å innføre resultatbasert finansiering i fattige land. Arbeidsgruppen skriver blant annet at slik finansiering kan stimulere til korrupsjon og føre til forsømmelse av verdifulle tjenester som ikke er inkludert i det som det betales for. Systematiske litteraturgjennomganger foretatt av forskere ved Kunnskapssenteret viser også mange uheldige effekter av resultatbasert finansiering (13).

En nylig gjennomført randomisert studie i Rwanda viser at tiltak basert på denne finansieringsstrategien førte til at flere kvinner fødte på institusjon og at flere barn oppsøkte helseinstitusjoner (14). Det kan imidlertid være vanskelig å generalisere fra et land som Rwanda, med en relativt sterk helsetjeneste med god giverfinansiering (15). Studien målte dessuten ikke konsekvenser for sykelighet og dødelighet.

Det finnes for øvrig liten evidens for at resultatbasert finansiering i seg selv har en effekt (16), og vi vet ikke om en slik strategi vil skape bærekraftige endringer (13). For land og initiativer som velger å benytte den, bør det legges inn tilstrekkelige midler til forskning som ikke bare evaluerer kortsiktig effekt av slik finansiering på den sykdommen eller tjenesten som intervensjonen er rettet mot, men som også vurderer den totale og langsiktig virkningen på helsetjenester, helse og overlevelse.

\section{Helhetlig helsetjeneste}

For å oppnå varige forbedringer i land med et svakt helsesystem og sviktende infrastruktur kreves en langsiktig satsing på et helhetlig helsevesen, i tillegg til målrettede tiltak for bedring av barne- og mødrehelse (17). Dette bør kombineres med endringsprosesser innen mange sektorer. Utdanningsfeltet er spesielt viktig. Uten et godt utdannet lederskap nasjonalt, både i helsesektoren og på andre områder, vil effektiv og bærekraftig bistand gjennom lokalt baserte programmer og partnerskap vanskelig la seg realisere.

Verdens helseorganisasjon (18) og andre $(19,20)$ går inn for å satse sterkere på en fornyet primærhelsetjenestestrategi. I 2009rapporten om de helserelaterte tusenårsmålene anbefales også en slik strategi (17, s. 17). I 2010-rapporten (21) påpekes nødvendigheten av større nasjonalt eierskap til ulike initiativer, noe også statsminister Jens Stoltenberg understreket i sin tale på FN-møtet for tusenårsmålene i New York 20.9. 2010 (22). Han påpekte at fattige land $\mathrm{i}$ høyere grad må bidra med egne ressurser gjennom å utvikle skattesystemet og motarbeide korrupsjon. 


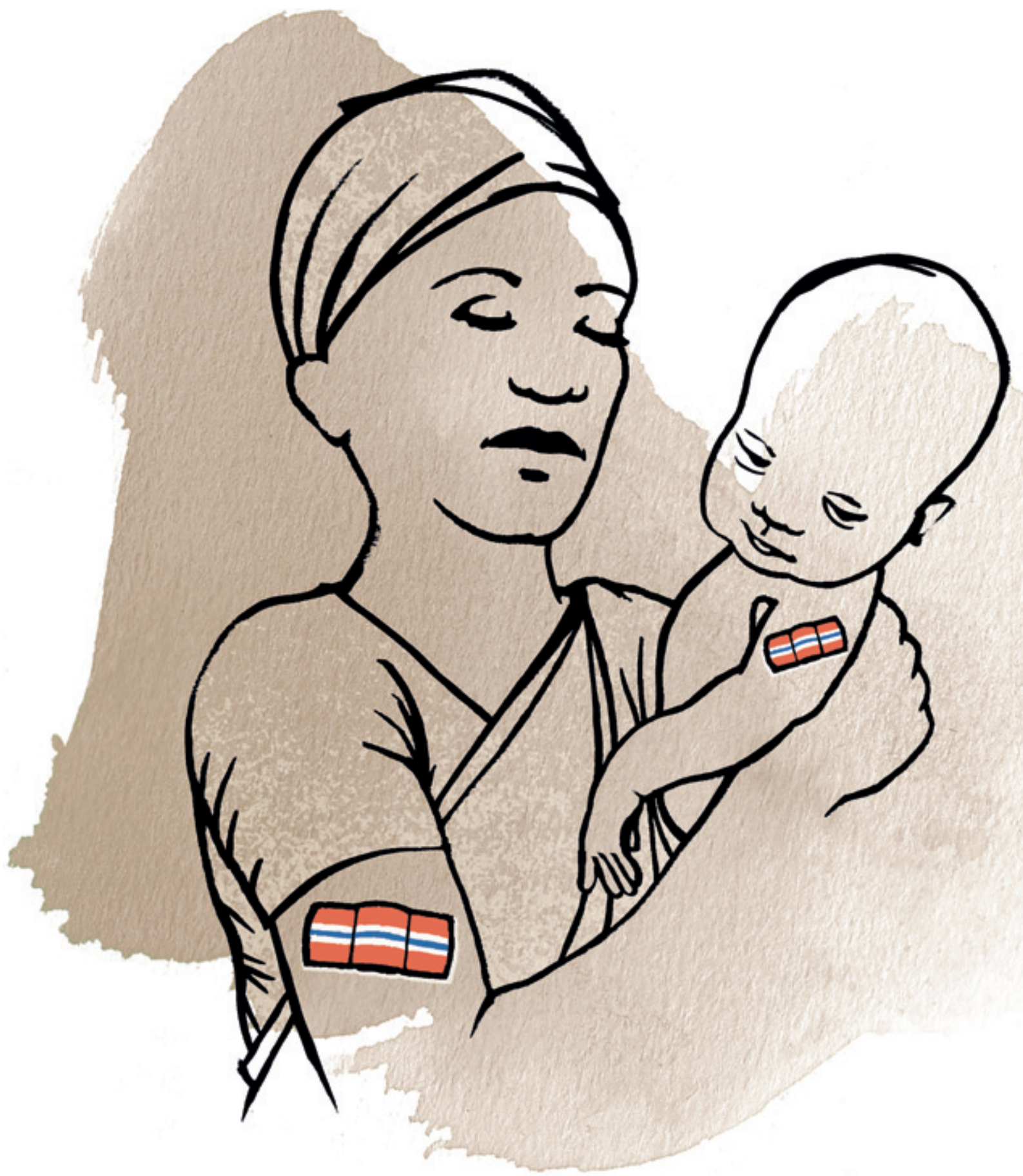

Illustrasjon Supernøtt Popsløyd

\section{Endringer i norsk helsebistand}

I prosessen med å utvikle store globale partnerskap for helse har Norges helsebistand raskt endret karakter. Vi har beveget oss bort fra brede satsinger på tverrsektorielle og helhetlige programmer i fattige land hvor norske aktører har lang erfaring med samarbeid og gode muligheter for å utvikle varige institusjonelle forbindelser. Nå går helsebistanden i større grad til utvalgte land der det satses på smalere intervensjoner, og der det legges mindre vekt på institusjonelle partnerskap og langsiktig kompetansebygging. Eksempler på dette er den store satsingen på tiltak for å bedre barne- og mødrehelse som nå introduseres i land som India, Pakistan, Tanzania og Nigeria.

Det kan diskuteres om dette er en riktig strategi. Fordelen er at man raskere kan få resultater å vise til på spesifikke områder. Det er mer usikkert hvordan effekten på helsevesenet vil være på lengre sikt. Det må likevel nevnes at Norge også satser på flere viktige globale initiativer, for eksempel gjennom den globale helsearbeideralliansen, på fondet mot aids, tuberkulose og malaria og gjennom GAVI-alliansen. Norge har dessuten tatt initiativ til å løfte frem helse som en viktig del av utenrikspolitikken (23). Disse og andre tiltak blir nærmere omtalt i Tidsskriftet $\mathrm{i}$ en egen artikkel om den globale helsearkitekturen (24).

\section{De fattigste}

Paul Collier påpeker i boken De fattigste (25) at vi primært bør rette vår oppmerksomhet mot den fattigste milliarden som mest trenger internasjonalt samarbeid og bistand. Også i 2009-rapporten om tusenårsmålene sies det nå klart at fremtidig bistand bør kanaliseres til lavinntektsland med de største helseproblemene (17, s. 52). Det kan faktisk være enklere å redusere sykelighet og dødelighet i slike befolkningsgrupper. Ved en kunnskapsbasert 
satsing, dvs. innføring med tilstrekkelig høy dekningsrad av tiltak som vi vet virker, vil vi i slike land forholdsvis raskt kunne oppnå lavere sykelighet og dødelighet, samt bedret ernæring. Dette er land som vi kanskje ikke ville velge å samarbeide med om vi primært skulle ta strategiske utenriks- eller handelspolitiske hensyn. For de fattigste er det imidlertid viktig at bistandssamarbeidet i første rekke styres av samarbeidslandenes humanitære behov, i tillegg til deres politiske vilje og deres evne til å gjennomføre slike tiltak.

Klimaendringene truer global helse I sin tale på FNs høynivåmøte for tusenårsmålene i New York høsten 2010 la statsminister Jens Stoltenberg også vekt på sammenhengen mellom klimaendringene og global helse (22). I en oversiktsartikkel i The Lancet omtales den globale oppvarmingen som den største trusselen mot global helse i det 21. hundreåret (26). Klimaendringene kan motvirke effekten av globale tiltak for bedre helse og utvikling, og forebygging av alvorlige klimaendringer er viktig for å bedre helse og utvikling i mange lavinntektsland. Dette omtales i en egen artikkel i denne temaserien (27).

\section{Bedre kunnskapsgrunnlag}

For å forstå hvordan man best kan gjennomføre nødvendige endringer kreves en sterkere satsing på implementeringsforskning med basis i nasjonale partnerinstitusjoner. Norge bør følge opp de nye initiativene med forskning som ikke bare måler de ulike tiltakenes egeneffekt, men også hvordan de best kan implementeres og oppskaleres på en effektiv måte. En mer rettferdig fordeling av helsefremmende tiltak slik at de i større grad når marginaliserte befolkningsgrupper, vil bidra til å øke den totale effektiviteten, siden disse gruppene oftest har den største sykdomsbyrden og kan ha spesielt stor nytte av slike tiltak. Ved å støtte forskningsbasert evaluering av nye så vel som av oppskalering av eksisterende intervensjoner, kan Norge bidra til at programmene tilpasses de lokale forholdene på en formålstjenlig måte og dermed styrke virkning og bærekraft. Langsiktig innsats forankret i lokale institusjoner er en nødvendig betingele. I stedet for store reformer når man ofte lenger med kunnskapsbaserte stegvise endringer tilpasset de lokale forhold i ulike land.

\section{Konklusjon}

Vi har sett en betydelig nedgang i barnedødelighet (5) og tegn til nedgang i mødredødelighet (28) i flere lavinntekts- og mellominntektsland. Nasjonale og internasjonale helseinitiativer har bidratt til denne fremgangen, spesielt når det gjelder nedgangen $i$ barnedødelighet. Fremgangen er imidlertid meget ulikt fordelt mellom land og mellom ulike befolkningsgrupper innen de fleste land
(5). Fattige land vil møte store helseutfordringer i de kommende tiår, også fordi vi i mange områder kan forvente større helseskader på grunn av klimaendringer (26).

Gjennom et fortsatt stort engasjement fra Norge og andre rike land, i tillegg til en gradvis omlegging av helsebistanden i en retning som foreslått i denne artikkelen, har vi tro på at Jonas Gahr Støre kan få rett når han i sin tale ved lanseringen av 2009-rapporten om de helserelaterte tusenårsmålene (17) uttrykte håp om at «this massive mobilisation for maternal health combined with the focus on health in general was a new beginning - a new initiative - to take the global health effort forward» (29).

\section{Gunnar Kvåle (f. 1942)}

er dr.med. og professor ved Senter for internasjonal helse, Universitetet i Bergen. Ingen oppgitte interessekonflikter.

\section{Halvor Sommerfelt (f. 1957)}

er lege og professor ved Senter for internasjonal helse, Universitetet i Bergen. Ingen oppgitte interessekonflikter.

\section{Litteratur}

1. Brugha R. Global health initiatives and public health policy. I: Carrin G, Buse K, Heggenhougen $\mathrm{KH}$, Quah SR, red. Health systems policy, finance, and organization. Amsterdam: Elsevier, 2009: 128-37

2. United Nations Development Programme. The millennium development goals. www.undp.org/mdg/basics.shtml (9.8.2011).

3. Støre JG. Internasjonalt krafttak for mødre og barn. Vårt Land 15.9. 2009. www.regjeringen.no/ $\mathrm{nb} / \mathrm{dep} / \mathrm{ud} / \mathrm{dep} /$ utenriksminister_jonas_gahr_ store/taler artikler/2009/krafttak moedre barn.html?id=577112 (9.8.2011).

4. Statsminsiterens kontor. Global kampanje for å redusere barne- og mødredødelighet. www.regjeringen.no/nb/dep/smk/

Aktuelle-temaer5/fns-tusenarsmal/ global-kampanje-for-a-redusere-barne-og.html?id=481756 (9.3.2011).

5. Bhutta ZA, Chopra M, Axelson $\mathrm{H}$ et al. Countdown to 2015 decade report (2000-10): taking stock of maternal, newborn, and child survival. Lancet 2010; 375: 2032-44

6. UNICEF. Donors commit $\$ 4.3$ billion to scale up GAVI Alliance's immunization efforts to 2015. www.unicef.org/immunization/index 58888.html (9.8.2011)

7. International Health Partnership. www.internationalhealthpartnership.net/en/home (7.6.2011)

8. International Health Partnership. Country planning cycle database. www.internationalhealthpartnership.net/en/news/ display/country_planning_cycle_database (9.8.2011).

9. Results-based finansing for health www.rbfhealth.org/rbfhealth/about (9.8.2011).

10. The World Bank Institute. More health for every dollar: results-based financing.

http://wbi.worldbank.org/wbi/stories/morehealth-every-dollar-results-based-financing (9.8.2011).

11. International Health Partership. Innovative results-based financing www.internationalhealthpartnership.net/en/ partners/innovative_resultsbased_financin (9.8.2011).

12. International Health Partnership. Task Force for innovative international financing for health systems. Working Group 1 Report: constraints to scaling up and costs. www.internationalhealthpartnership.net/en/ taskforce/taskforce reports (9.8.2011).

13. Oxman AD, Fretheim $A$. Can paying for results help to achieve the Millennium Development Goals? Overview of the effectiveness of results-based financing. J Evid Based Med 2009; 2: 70-83.

14. Basinga P, Gertler PJ, Binagwaho A et al. Effect on maternal and child health services in Rwanda of payment to primary health-care providers for performance: an impact evaluation. Lancet 2011 377: $1421-8$

15. Montagu D, Yamey G. Pay-for-performance and the Millennium Development Goals. Lancet 2011 377: $1383-5$

16. Oxman AD, Fretheim A. Can paying for results help to achieve the Millennium Development Goals? A critical review of selected evaluations of resultsbased financing. J Evid Based Med 2009; 2: 184-95.

17. Leading by example - protecting the most vulnerable during economic crisis. The global campaign for the health millennium development goals, 2009. Accessed through: www.helsedirektoratet.no/internasjonal_helse/ rsrapport_2009_leading_by_example protecting the most vulnerable during the economic crisis_284524 (9.8.2011).

18. World Health Organization. World Health Report 2008. Primary Health Care - Now more than ever WHO, Genève: , WHO, 2008. www.who.int/whr/ 2008/en/index.html (9.8.2011)

19. Movement PH. Global Health Watch 2. An alternative world health report. London: Zed Books, 2008 www.ghwatch.org/ghw2 (9.8.2011).

20. Bhutta ZA, Ali S, Cousens $S$ et al. Alma-Ata: Rebirth and Revision 6 Interventions to address maternal, newborn, and child survival: what difference can integrated primary health care strategies make? Lancet 2008; 372: 972-89.

21. The Global Campaign for the Health Millennium Development Goals 2010. Putting the global strategy for women's and children's health into action. Oslo: Utenriksdepartementet, 2010.

22. Stoltenberg J. Tale til FNs generalforsamling 20.9 . 2010. www.regjeringen.no/en/dep/smk/ Whats-new/Speeches-and-articles/ statsministeren/statsminister_jens_stoltenberg/ 2010/un-high-level-summit-on-the-millenniumd. html?id=614634 (9.8.2011).

23. Sandberg KI, Andresen S, Steen SH et al. Helse som utenrikspolitikk. Tidsskr Nor Legeforen 2011 131: 1784-6

24. Møgedal S, Alveberg B, Pereira C. Den globale helsearkitekturen - til nytte for alle? Tidsskr Nor Legeforen 2011; 131: 1660-2.

25. Collier P. De fattigste. Veien ut av uføret. Oslo: Gyldendal, 2008.

26. Costello A, Abbas M, Allen A et al. Managing the health effects of climate change. Lancet 2009; 373 : 1693-733.

27. Kvåle G, Fadnes LT, Tryland M et al. Klimaendrin ger - vår tids største helsetrussel. Tidsskr Nor Legeforen 2011: 131: 1670-2.

28. World Health Organization, UNICEF, UNFPA, The World Bank. Trends in maternal mortality: 1990 to 2008. Estimates developed by WHO, UNICEF, UNFPA and The World Bank. Genève: WHO, 2010.

29. Støre JG. Report of the Global campaign for the health millennium development goals 2009: leading by example - protecting the most vulnerable during the economic crisis. Tale, New York, 15.6. 2009. /www.regjeringen.no/nb/dep/ud/dep/ utenriksminister jonas gahr store/taler artikler/ 2009/health_goals.html?id=572399 (9.8.2011).

Mottatt 23.6. 2011, første revisjon innsendt 3.8. 2011, godkjent 4.8. 2011. Medisinsk redaktør Trine B. Haugen. 